\title{
Los negocios de la casa Hainsworth y Compañía en Tacna y Arica, 1841-1868. Una mirada al comercio regional ${ }^{*}$
}

\section{The Business of the House Hainsworth and Company in Tacna and Arica, 1841-1868. A Look at Regional Trade}

\author{
Jaime Rosenblitt B. \\ Centro de Investigaciones Diego Barros Arana, Dirección de Bibliotecas, \\ Archivos y Museos de Chile, Santiago, Chile, e-mail: jaime.rosenblitt@dibam.cl
}

\begin{abstract}
Resumen. Este artículo recorre las actividades de la casa Hainsworth y Compañía, para explicar las razones de su éxito comercial y cuáles fueron los elementos que la distinguieron de otras empresas y mercaderes extranjeros que actuaron en la región Tacna-Arica en la misma época. En la narración aparecen inversionistas con intereses a lo largo de la costa del Pacífico sudamericano, comerciantes medianos en busca de oportunidades para ocupar un lugar en la minería, vendedores al menudeo, arrieros y empresarios mineros de distintos niveles técnicos. Todos ellos en busca de fortuna.
\end{abstract}

Palabras clave: Hainsworth y Compañía; región Tacna-Arica; Perú; Pacífico sudamericano; comercio; siglo XIX.

Abstract. This article traces the activities of Hainsworth and Company to explain the reasons for its commercial success and which were the elements that distinguished it from other foreign companies and merchants who acted in the Tacna-Arica region at the same time. The narrative includes investors with interests throughout the South American Pacific coast, medium-sized traders looking for opportunities to occupy a place in mining, retailers, muleteers and mining entrepreneurs of different levels of technicians. All of them looking for fortune.

Key words: Hainsworth and Company; Tacna-Arica region; Peru; South American Pacific; trade; $19^{\text {th }}$ Century.

JEL: N8; N76; N86; N96.

* Este texto es resultado del proyecto de investigación postdoctoral Fondo Nacional de Desarrollo Científico y Tecnológico (FONDECYT) número 3140234, al que agradecemos su apoyo. Algunos antecedentes que se utilizan ya han sido citados en Rosenblitt (2017a, 2017b).

Am. Lat. Hist. Econ., sep.-dic., 2017, pp. 41-70 | DOI: 10.18232/alhe.v24i3.865 
Fecha de recepción: 6 de marzo de 2017. Fecha de aceptación: 24 de abril de 2017.

\section{INTRODUCCIÓN}

$\mathrm{E}$ $\mathrm{n}$ algunos de los textos que se citan a continuación (Rosenblitt, 2010, 2012, 2013a, 2013b y 2014) se ha descrito y analizado la evolución del comercio en la región Tacna-Arica entre 1776 y 1841, es decir, desde la formación de un segmento de mercaderes criollos ajeno al influjo del comercio limeño, hasta que el sector comenzó a ser copado por empresarios extranjeros especializados en la colocación de importaciones y abocados a controlar el comercio exterior boliviano. Este artículo se dedica a examinar dicho proceso a través de los negocios emprendidos por la casa Hainsworth y Compañía, que se desempeñó en la región Tacna-Arica entre las décadas de 1840 y 1860 , alcanzando notable éxito si se considera que después de nueve años de existencia su capital inicial se había multiplicado 8.5 veces.

Junto a su cometido económico, es interesante indagar el caso de Hainsworth y Compañía porque a través de sus actividades esta firma británica se vinculó con múltiples actores que sintetizan las características del comercio regional entre 1841 y 1868 . Aparecen capitalistas anglosajones posicionados en los circuitos de exportación de materias primas; comerciantes europeos y criollos especializados en la distribución de importaciones y en búsqueda de oportunidades para invertir sus utilidades en la minería; mercaderes medianos que venden a escala local y regional alimentos y licores junto a las manufacturas que obtenían de los empresarios primados; mineros de diverso origen y magnitud dedicados a explotar vetas de cobre y depósitos de salitre, para lo cual recurrían al apoyo financiero de los comerciantes, y modestos arrieros indígenas y mestizos que aspiraban a mejorar su condición complementando los servicios de transporte con pequeñas ventas por cuenta propia.

Luego, interesa conocer cómo Hainsworth se relacionó con este heterogéneo conjunto de actores para alcanzar negocios exitosos en una región que pasó de disponer de ventajas institucionales para controlar el comercio exterior de Bolivia e invertir sus utilidades en los circuitos de exportación de materias primas de ese país, a un escenario en el que estas condiciones fueron desapareciendo, forzando a los más prominentes mercaderes de Tacna y Arica a redefinir sus actividades y buscar nuevos horizontes de inversión. Por lo tanto, este artículo se propone reconstruir algunas operaciones realizadas por la casa Hainsworth y su predecesora, Hegan y Compañía, en la región Tacna-Arica entre 1841 y 1868 para mostrar las características del comercio regional en todos sus niveles, y luego 
identificar su modelo de negocios, así como las decisiones y circunstancias que explican el éxito alcanzado.

Dicha reconstitución se basa en los registros notariales de Tacna y Arica, que se complementan con antecedentes fragmentarios de origen judicial y contable. El entorno político regional, por ahora sólo conocido superficialmente, lo proporcionan algunos estudios monográficos, cartas y memorias, referencias de la historiografía del siglo XIX peruano y notas en la prensa de Tacna y Arequipa que ofrecen una visión sobre el ambiente político en que se desenvolvió el comercio regional. La falta de estadísticas económicas para los años de estudio (Bonilla, 1977, p. 85) impide tener una noción clara sobre las dimensiones del comercio regional y saber qué porción de este ocuparon los intereses de Hainsworth y Compañía. Para disponer de un referente sobre el comportamiento de la economía regional durante el periodo examinado, se ha tenido a la vista el estudio de Juan Castro Barreda (1995) que recopila los antecedentes fragmentarios sobre los ingresos de aduana y movimiento portuario en Arica disponibles en el Fondo Hacienda del Archivo General de la Nación de Perú, y se complementa con las estadísticas comerciales proporcionadas por los cónsules británicos y la información de entrada y salida de naves de Arica publicada en la prensa regional. No obstante el valor de esta recopilación, carecemos de información detallada para dimensionar los negocios de Hainsworth y Compañía. Por ello, y dada la naturaleza de las fuentes empleadas, la siguiente aproximación es cualitativa y las cuantificaciones sugeridas son apenas comparaciones con las actividades de otros empresarios.

\section{BOSQUEJO HISTÓRICO DEL COMERCIO EN LA REGIÓN TACNA-ARICA}

Hasta su separación definitiva entre Perú y Chile en 1929, el eje que formaban las ciudades de Tacna y Arica, junto con su entorno geográfico, entre el altiplano y la costa, poseía ventajas para haberse convertido en un importante núcleo comercial en el Pacífico sudamericano. Por su ubicación, casi al centro del continente, y dada la distancia de Lima-El Callao y Santiago-Valparaíso, el espacio tacnoariqueño se especializó en la atención del comercio exterior del Alto Perú y de parte importante del sur peruano, integrándose con esas economías mediante la prestación de servicios portuarios, el suministro de los alimentos, vinos, licores y aceites producidos en la región, y la ocupación de sus habitantes en el comercio y transporte. Su principal vínculo fue con las regiones mineras altiplánicas, y consistía en que estas despachaban su producción a través del puerto de Arica y por él ingresaban todos las importaciones que demandaban. La dinámica de 


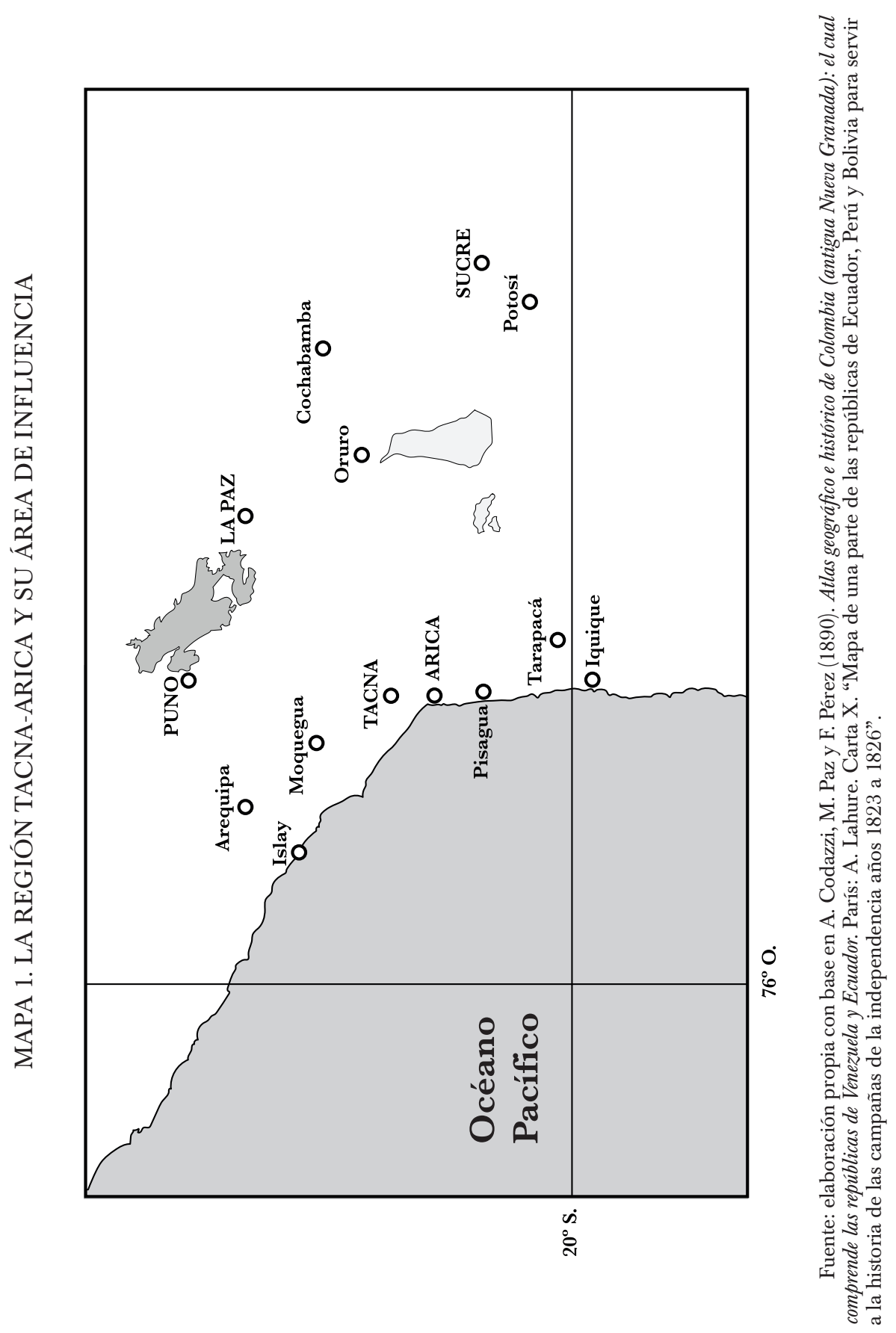


esta circulación estimuló la economía regional, la creación de infraestructura urbana y territorial y el poblamiento (Rosenblitt, 2013a, pp. 22-23).

Por sus cualidades geográficas, durante la colonia Arica participó en la articulación del espacio económico peruano. Desde 1575 comenzó a servir como puerto de embarque para la producción argentífera de Potosí y de desembarque del azogue requerido en Charcas. Este flujo era administrado por una Caja Real que despachaba remesas de plata a Lima y recaudaba los tributos en todo el partido. En 1592 se crearon bodegas para almacenar mercurio, y en 1596 se instaló un tribunal de cuentas para supervisar el flujo de caudales, pagar sus salarios a los militares asignados al puerto y supervisar el traslado del situado para el ejército de Chile (Assadourian, 1982, pp. 157-158). Las malas condiciones ambientales, recurrencia de eventos sísmicos y ataques de piratas obligaron en 1711 a trasladar este aparato administrativo hasta Tacna, 57 kilómetros al noreste. Dicha villa, dotada de un clima más benigno, atrajo el asentamiento de parte importante de la población blanca de Arica, que se dedicó de preferencia a la agricultura y la arriería (Vargas, 1956, pp. 73-74).

A partir de la década de 1780, como consecuencia de las reformas administrativas introducidas por los monarcas Borbones, la región TacnaArica contó con un grupo de empresarios especializados en el comercio. La apertura de Arica al intercambio con otros puertos imperiales favoreció el masivo arribo de importaciones, disminuyendo la gravitación del comercio de Lima sobre la economía regional; un año antes, la obligación impuesta a los mineros de la meridional provincia de Tarapacá, de fundir su producción bruta de plata en la Caja Real de Arica, permitió a algunos mercaderes de Tacna tomar parte en el negocio, acumular un excedente en metales preciosos y convirtió a Tarapacá en un atractiva plaza para las manufacturas y la producción agrícola regional (Rosenblitt, 2014, pp. 50-62). En 1784 la abolición de los corregimientos eliminó la figura de un funcionario colonial que había monopolizado el comercio con el altiplano, permitiendo el acceso de actores locales a ese mercado (Moreno, 1977, pp. 448-450). Aunque en las siguientes décadas coloniales estos flujos se fortalecieron, los mercaderes regionales fueron desplazados por comerciantes limeños y peninsulares que contaban con una abundante oferta, mejores precios y punzantes estrategias mercantiles (Rosenblitt, 2014).

El fin del régimen colonial y el advenimiento de la república en Perú impusieron un escenario muy distinto: la apertura del tráfico directo con los países desarrollados, el surgimiento de Valparaíso como centro de despacho de importaciones en el Pacífico sudamericano y la pérdida de gravitación de los mayoristas peninsulares y limeños, permitieron a los mercaderes locales volver a ocupar un lugar en la comercialización regional de manufacturas, insertarse en las redes mercantiles organizadas por casas 
extranjeras e incluso integrarse en los circuitos de explotación y transferencia de materias primas, rubro hacia el que numerosas firmas noratlánticas enfocaron sus operaciones e inversiones (Bonilla, 1977, pp. 77-78; Cavieres, 1988, p. 68). Junto a estas transformaciones, la más importante fue el surgimiento de Bolivia como un Estado distinto y la consiguiente separación del eje Tacna-Arica de lo que había sido su mercado natural, para cuyo acceso comenzó a ser necesario influir en el naciente Estado nacional y enfrentar a regiones con intereses distintos, cuando no opuestos (Nugent, 1976 [1866], p. 259; Rosenblitt, 2010, pp. 83-85).

El comercio con Bolivia se transformó en un tema controversial en el debate durante la temprana república peruana, ya que mientras las regiones meridionales buscaban obtener un estatuto de intercambio liberal, que facilitara el tránsito entre costa y altiplano, Lima, las provincias productoras de azúcar del norte, los antiguos mercaderes monopólicos y la mayoría de los caudillos militares activos, eran partidarios del proteccionismo, tanto para proteger de la competencia exterior a los grupos de interés y regiones que representaban, como para recaudar ingresos fiscales, vía aranceles, con los que financiar sus ejércitos (Aljovín, 2000, pp. 252-253; Gootenberg, 1997, pp. 73-74).

La Confederación Perú-Boliviana (1836-1839) y su proyecto geopolítico, situó al comercio tacnoariqueño en un escenario que satisfacía sus aspiraciones, al adoptar un régimen favorable al comercio libre, pero que precisaba de un considerable respaldo político, cuando no militar, para sostenerse y que la región no fue capaz (o no tuvo la voluntad) de brindarle. En cambio y privilegiando la obtención de la estabilidad institucional, sus principales mercaderes optaron por ganarse el favor de los militares que conquistaron el poder en 1845 (Rosenblitt, 2012, p. 220; Sobrevilla, 2015, pp. 190-192; Tantaleán, 2011, p. 83). En este sentido resulta gravitante la figura de Ramón Castilla, militar cuya carrera se había identificado con el proteccionismo, pero que una vez alcanzado el poder con el respaldo de los incipientes capitales salitreros de su natal Tarapacá y de los principales mercaderes de Tacna y Arica, ${ }^{1}$ se allanó a admitir un sistema de comercio liberal, pues el comienzo de las exportaciones de guano, acicateadas por la

\footnotetext{
${ }^{1}$ Durante la planificación de la guerra que los generales Castilla y Nieto iniciaron contra el gobierno de Manuel Ignacio Vivanco, el primero señala que los recursos para financiarla saldrán de la provincia de Tarapacá, en particular de los empresarios salitreros, entre los que tenía varios conocidos y partidarios, véase Carta de Ramón Castilla a Domingo Nieto, 20 de mayo de 1843, caja 31, vol. 125, fs. 526-528, Archivos Documentales, Biblioteca Nacional de Chile. Al frente de la Prefectura de Tacna y cumpliendo la función de organizar la defensa del puerto de Arica, el coronel Pedro Cisneros informa a Nieto que ha logrado financiar sus fuerzas extrayendo los pocos recursos disponibles en la aduana de Arica y con un préstamo obtenido de los mercaderes extranjeros de Tacna, garantizado con los ingresos futuros de esa misma aduana, véase Carta de Pedro Cisneros a Domingo Nieto, 15 de julio de 1843, en McEvoy (2015, t. I, pp. 310-313).
} 
demanda de fertilizantes en los países que iniciaban procesos de industrialización y concentración urbana, anunciaba una nueva etapa en la historia de Perú (Bonilla, 1994, pp. 38-45).

Luego de poner fin a casi veinte años de guerras civiles, el primer gobierno de Ramón Castilla (1845-1851) otorgó al comercio tacnoariqueño facilidades para fortalecer el intercambio con Bolivia. La principal era que se admitía el desembarco en Arica de mercadería en tránsito hacia ese país y, tal como durante toda la colonia, para que continuaran fluyendo las exportaciones altiplánicas hacia el Pacífico. Para Bolivia estas condiciones constituían la mejor alternativa portuaria de integración a la economía mundial. Así, al promediar la década de 1840 la región Tacna-Arica adquirió una dinámica autónoma de la economía radicada en Lima y Perú central, más dependiente de las condiciones para el intercambio con Bolivia que de las oscilaciones del ciclo del guano (Nugent, 1976 [1866], p. 260).

Pero este virtual régimen de libre comercio entre Tacna-Arica y Bolivia, así como los privilegios otorgados a los extranjeros, no pasaron inadvertidos para otras regiones. En particular Arequipa, que se sentía derrotada y menoscabada, denunciaba estas prebendas en el mismo tono que manifestaba su rechazo al gobierno de Castilla, pues consideraba que gobernaba en favor de quienes habían financiado su ascenso al poder. Estas quejas provenían en especial de los mercaderes criollos de Arequipa, que hasta el fin de la colonia habían controlado parte importante de la demanda altiplánica por vinos y licores, de la que fueron desalojados por la competencia extranjera y la falta de innovación técnica de los viñateros regionales (Condori, 2014, pp. 168-170 y 180).

Salvo los relatos que entrega Juan Gualberto Valdivia sobre los levantamientos de Castilla y Domingo Nieto contra el gobierno de Manuel Ignacio Vivanco, en 1843, y la revolución de Castilla contra el gobierno de José Rufino Echenique, en 1854 (Valdivia, 1874, pp. 274-275, 312-314), no existen antecedentes historiográficos que muestren recelos de la elite arequipeña hacia los extranjeros de Tacna y Arica, ni a una competencia entre ambas regiones por dominar del comercio exterior boliviano. En cambio, la prensa regional ofrece varios indicios que abonan dicha hipótesis. Desde 1842, a través de editoriales y crónicas, la prensa de Arequipa hizo notar la contradicción entre las tensiones diplomáticas peruano-bolivianas y las granjerías que disfrutaban los productos agrícolas y manufacturados que ingresaban a ese país a través de Arica. Cuando a comienzos de 1847 el Congreso peruano sancionó la creación de una aduana común en Arica, un articulista arequipeño sintetizó la situación en que quedó su provincia e identificó a los responsables: 
Arica no debe jamás abastecer los mercados de Bolivia, bajo las bases que hasta ahora ha hecho el comercio, pues esto es una verdadera ruina del departamento de Arequipa, por cuanto no hay modo de evitar el contrabando que tan sólo favorece a cuatro monopolistas extranjeros establecidos en Tacna. Si se importa a Bolivia efectos ultramarinos que entran por Arica, sea pagando en este puerto los derechos que se adeudaría por los importados a nuestro territorio, pues no hay razón para que se deteriore un país para que prospere otro. ${ }^{2}$

Más evidencia sobre la rivalidad entre Arequipa y Tacna-Arica, se encuentra en la prensa boliviana que promovía la idea de anexionar los departamentos de Moquegua y Tarapacá. Rebatiendo esta denuncia, un editorialista tacneño reprodujo el emplazamiento recibido de un redactor de Cochabamba:

No podemos excusarnos de hacerle una pregunta; si el puerto de Arica perteneciendo al Perú es hostilizado por Arequipa con el fin "de conquistarle a mano armada los mercados del Cuzco y Puno para auxiliar los progresos de Islay, fijar su comercio en esa plaza, y regular a su albedrío los intereses de sus vecinos", ¿cómo es que pasando este departamento a ser propiedad de Bolivia, "Arica sería el único puerto de importación y exportación para Arequipa, Cuzco, Puno y Tacna la única vía mercantil para aquellos departamentos?"3

No obstante esta tensión, las siguientes dos décadas fueron las más prósperas del comercio tacnoariqueño, que llegó a controlar casi 75\% de las exportaciones de Bolivia y parte importante de las importaciones y alimentos consumidos en ese país (Castro, 1995, pp. 121-122). A partir de 1860 este ciclo comenzó a declinar, como consecuencia de la influencia que la elite arequipeña ganaba en la conducción del Estado peruano, que recuperaba poder político a medida que los ingresos del guano comenzaron a experimentar fuertes oscilaciones luego de que su extracción y comercialización fue confiada a "consignatarios" limeños (Contreras, 2015, pp. 122-125). El primer golpe al comercio tacnoariqueño fue la instauración del sol como moneda oficial en reemplazo del antiguo peso de plata de ocho reales, pues a partir del 1 de enero de 1863 se prohibió la circulación de otras monedas, en directa alusión al peso boliviano, de intenso uso en la región (Contreras, 2012, p. 43). Dos años después, ambos gobiernos suscribieron un tratado que eliminó la figura de "productos en tránsito a Bolivia" e impuso un arancel a los bienes desembarcados hacia ese país (Castro, 1995, pp. 16-17). En mayo de 1868 comenzaron las obras del fe-

${ }^{2}$ El Pabellón Nacional, 9 de abril de 1847.

${ }^{3}$ El Moqueguano, 12 de noviembre de 1845. 
rrocarril entre Arequipa y la caleta de Mollendo, que en 1874 se extendió hasta la orilla del lago Titicaca (Contreras, 2012, p. 121). Estas decisiones terminaron por arrebatar el comercio exterior boliviano a Tacna y Arica para entregárselo a Arequipa. Dichas transformaciones fueron comprobadas en 1877 por un viajero europeo, que antes de abordar el ferrocarril en Puno con destino a Arequipa, observó cómo se estibaban las varillas de cobre de Corocoro rumbo a Mollendo, desde donde se embarcarían a Europa (Wiener, 1993, p. 472).

Pero el colapso del comercio de Tacna y Arica no fue sólo consecuencia del resentimiento de la elite criolla de Arequipa ${ }^{4}$ y las decisiones nacionales en materia económica. El 5 de mayo de 1868 un terremoto, seguido por una enorme marejada, destruyó las instalaciones portuarias de Arica, el ferrocarril a Tacna y toda la infraestructura de apoyo al comercio. Luego de la catástrofe tuvo lugar una epidemia de fiebre amarilla, que se extendió por dos años y provocó el abandono de la mayoría de los mercaderes extranjeros. Cuando los daños causados por la tragedia de 1868 comenzaban a superarse, el 13 de agosto de 1877 un nuevo sismo, seguido de una gran ola, volvió a destruir todo lo recuperado (Fernández, 2017, pp. 493-565). Y dos años más tarde comenzó la guerra del Pacífico, que asoló la región, su economía y terminó por desarticularla hasta el presente.

\section{EL COMIENZO DEL APOGEO DEL INTERCAMBIO}

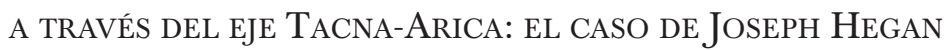

Con el afianzamiento de Ramón Castilla en la primera magistratura de Perú en 1845 y las finanzas públicas aliviadas con el inicio de las exportaciones de guano, el grupo de mercaderes extranjeros asentados en el eje Tacna-Arica desde la década de 1830 comenzó a explotar las ventajas geográficas y políticas de la región. Junto con aprovechar los flujos de intercambio entre costa y altiplano para articular la colocación de manufacturas y el despacho de materias primas, extendieron su influencia hacia la vecina Moquegua y sus valles productores de vino y aguardiente, y a la meridional Tarapacá, que comenzaba un despegue económico con el inicio de las exportaciones de salitre, que llegaron a opacar la gravitación del guano en el mercado mundial de fertilizantes.

\footnotetext{
${ }^{4}$ Una buena descripción del sector comercial arequipeño hacia la primera mitad del siglo XIX la ofrece Víctor Condori (2014), quien muestra que las casas mercantiles extranjeras, al igual que en Tacna y Arica, se asentaron a partir de la distribución de efectos de ultramar, y luego asumieron el control de las exportaciones de lana procedente de Cuzco y Puno a través de las caletas de Quilca e Islay. Mientras que los comerciantes locales desplazados se enfocaron en la demanda por importaciones en sectores periféricos de la región y provincias vecinas.
} 
La mayoría de los extranjeros que operaban en Tacna y Arica lo hacían en representación o asociados con firmas mercantiles de Valparaíso, que les proporcionaban importaciones y despachaban las materias primas a Europa. Aunque el caso del inglés Joseph Hegan no encuadra totalmente en esta tipología, destaca por el éxito alcanzado y es útil para ilustrar las alternativas que ofrecía la región durante las primeras décadas republicanas. Su aparición en Tacna se remonta al 20 de mayo de 1825, cuando formalizó la compra de un esclavo para ayudarlo en la bodega que pocas semanas después inauguró. Las manufacturas allí almacenadas eran suministradas a arrieros que viajaban hacia Bolivia, Arequipa y Moquegua mediante créditos que no excedían los seis meses a 3\%. Estos adelantos o habilitaciones eran similares a los empleados por los mercaderes coloniales, salvo que cada operación era registrada ante un notario, cada contraparte comprometía multas en caso de no cumplir la deuda y a garantizarla con la hipoteca de bienes inmuebles. Al parecer, este sistema no brindó a Hegan las utilidades que esperaba obtener, por lo que a partir de diciembre de 1826 designó apoderados que lo representaran ante posibles clientes en Bolivia y Arequipa (Rosenblitt, 2013a, pp. 238-239).

$\mathrm{Al}$ año los intereses de Hegan habían crecido en volumen y complejidad. Gracias a la ayuda en Lima de su hermano John, comenzó a ofrecer cacao y, mediante un contrato con el moqueguano Lucas Fernández, obtuvo el suministro de 1000 arrobas anuales de aceite. Ambos productos eran apetecidos en Bolivia e invirtió sus utilidades en corteza de cascarilla, asociándose con el tarapaqueño Manuel Loayza, que tenía una licencia del gobierno boliviano para exportar ese insumo farmacéutico e industrial. Para entonces la estrategia comercial de Hegan se diferenciaba de la de los demás mercaderes británicos de Tacna y Arica, pues no recurría a las casas de Valparaíso para articular sus negocios y despachaba desde Arica las materias primas que controlaba. Para obtener manufacturas recurría a una red de contactos que lo alertaba de las oportunidades que surgían en los puertos atlánticos (Rosenblitt, 2013a, pp. 239-240).

El despegue de los negocios de Hegan tuvo lugar en octubre de 1833, cuando se trasladó a Liverpool. Mientras tanto, sus intereses en Perú quedaron al cuidado de John, quien dos meses antes había formado la sociedad Hegan \& Hall, dedicada a los negocios mineros y cuya primera actividad fue la compra de varias estacas de cobre en el asiento de Choquelimpe, en la precordillera frente a Arica, y la designación de William Hillman como agente en Valparaíso, encargado de encontrar compradores para la producción futura y adquirir insumos para las faenas. Tiempo después, la firma se asoció con el experto George Smith para poner en marcha dos oficinas salitreras en Tarapacá. En 1836 Hegan rediseñó sus inversiones mineras y abandonó todo intento de explotar por su cuenta vetas de cobre y de- 
pósitos de nitrato. En cambio, se concentró en aprovechar sus fortalezas, que eran habilitar con créditos a mineros más avezados y comercializar su producción a través sus contactos (Rosenblitt, 2013a, p. 241).

$\mathrm{Al}$ parecer, durante el periodo de la Confederación Perú-Boliviana (1836-1839) las actividades de Hegan y Hall estuvieron paralizadas pues, por lo menos en Tacna, no aparecen en los registros notariales. Pero una vez disuelta dicha entidad política, se multiplicaron las operaciones de adelanto de manufacturas a mercaderes criollos y británicos de La Paz, Cochabamba y Oruro. En octubre de 1842 la firma contrató a James Hainsworth, quien asumió su representación para formalizar convenios de habilitación comercial y minera y cobrar deudas. Para ello, el inglés de 28 años debía penetrar y darse a conocer en la comunidad mercantil tacnoariqueña y adentrase en el funcionamiento de los sistemas legales peruano y boliviano. ${ }^{5}$

Los indicios disponibles apuntan a que Hainsworth tuvo un desempeño destacado, pues a partir marzo de 1853 las escrituras públicas lo señalan como "socio y representante de Hegan y Compañía". El documento que inaugura su nueva condición es además relevante, porque se le encomienda negociar con las autoridades bolivianas una licencia para exportar corteza de cascarilla. ${ }^{6}$ Como se sabe, la obtención de esta concesión era compleja, pues los aspirantes debían influir en una decisión discrecional de ese gobierno, por lo que era frecuente que abandonaran estas gestiones para asociarse con algún particular que ya tuviese el beneficio. ${ }^{7}$ Los esfuerzos de Hainsworth sólo dieron frutos en 1861, cuando ya había emprendido un camino propio y encontrado en el argentino Andrés Novillo un aliado perfecto. ${ }^{8}$

Sin embargo, este episodio no pasó de ser una anécdota en el rumbo que tomaron los negocios de Hegan. En noviembre de 1852, mientras navegaba hacia Liverpool, Hainsworth culminaba las tratativas con el gobierno peruano para adjudicarse la ampliación del puerto de Arica (Díaz,

\footnotetext{
${ }^{5}$ Poder para cobrar deudas, Tacna, 27 de octubre de 1842. Fondo Notarial de Arica (en adelante FNA), vol. 98, fs. 173v.-174v., en Archivo Histórico Nacional de Chile (en adelante AHNCH).

${ }^{6}$ Poder para negociar con el gobierno boliviano, Tacna, 11 de marzo de 1853. FNA, vol. 130, fs. 165-166v., AHNCH.

${ }^{7}$ El comerciante alemán Heinrich Witt (1992, vol. II, p. 291) relata en su diario que para despachar la corteza hasta Liverpool, en 1847, recurrió a Ildefonso Villamil, un español que tenía la licencia del gobierno. Exámenes químicos practicados a una muestra de la partida de 7500 pesos que adquirió, arrojaron $2 \%$ de contenido de quinina, de regular calidad pero útil para fines industriales. Al llegar a Liverpool el producto fue rechazado por los compradores, que lo consideraron inservible. Al recordar, Witt especula que la corteza no debió estar bien enfardada por lo que durante la travesía resultó malograda.

${ }^{8}$ Poder de representación, Tacna, 7 de marzo de 1861. FNA, vol. 161, fs. 25-25v., AHNCH.
} 
Ruz, Galdames y Tapia, 2012, p. 166). ${ }^{9}$ Esta iniciativa representó el paso previo para obtener un contrato mucho mayor: la construcción del ferrocarril de Tacna a Arica. Con el adelanto de 2000000 de pesos peruanos de ocho reales en bonos del gobierno, a 4.5\% anual, Hegan logró atraer en Londres a otros inversionistas, reunir suficientes recursos para financiar las obras y retirar utilidades inmediatas, pues en la Bolsa inglesa los papeles de la deuda peruana se cotizaban a 6\% (Quiroz, 2013, pp. 180-181).

Suscrito el convenio el 12 de junio de 1853, los trabajos comenzaron en octubre siguiente bajo la dirección de Hainsworth. Sus tareas eran claras pero no siempre sencillas. Debía encargarse de desembarcar el material que Hegan despachaba desde Inglaterra, adquirir los terrenos donde se tenderían los rieles y entenderse con los ingenieros a cargo de la obra, que resultó ser la más problemática de todas. Estos fueron el bonaerense Guillermo Eugenio Billinghurst y el estadunidense George Taylor. ${ }^{10}$ Ambos vivían en Arica cuando fueron contratados por Hainsworth, prestaban servicios en las obras portuarias de Arica y cada uno había recibido un préstamo de Hegan para comprar acciones de la compañía, que tendría por 30 años los derechos exclusivos de explotación del ferrocarril que estaban construyendo. Esta doble condición, de empleados y accionistas, generó permanentes reclamos de Billinghurst y Taylor por las condiciones de sus contratos, obligando a Hainsworth a negociar modificaciones y, simultáneamente, presionarlos con la deuda con Hegan. ${ }^{11}$

Hainsworth debió prestar dedicación exclusiva a la construcción del ferrocarril, pues mientras avanzaban los trabajos la firma enfrentaba dificultades no previstas. Una de estas fue el conflicto suscitado con los obreros chilenos contratados para las faenas. En agosto de 1855 desembarcaron en Arica 27 peones y dos mujeres que debían emplearse en los trabajos, pero el avance de estos los hacía innecesarios, por lo que la actitud seguida por Hegan y Compañía fue inducirlos a firmar convenios con salarios inferiores a los acordados originalmente, a diferir los pagos y a expulsarlos de las faenas. Los trabajadores denunciaron esta situación al cónsul chileno en Arica, Carlos Basadre, quien la transmitió a las autoridades departamentales y comenzó a gestionar ayuda para los infortunados. Para ello, organizó un campamento en la playa al sur del puerto, donde los desdichados sobrevivieron hasta febrero de 1856, cuando fueron repatriados por su gobierno, logrando rescatar apenas una fracción del dinero reclamado. Por

\footnotetext{
${ }^{9}$ El Peruano, 3 de abril, 1 de mayo y 24 de julio de 1852. Poder para negociar ejecución de obras portuarias, Tacna, 2 de noviembre de 1852. FNA, vol. 126, fs. 380-382, AHNCH.

${ }^{10}$ Modificación contrato, Tacna, 4 de mayo de 1854. FNA, vol. 100, fs. 357-357v. El contrato inicial fue suscrito en Lima el 16 de junio de 1851, AHNCH.

${ }^{11}$ Reconocimiento de deuda, Tacna, 18 de abril de 1854. FNA, vol. 100, fs. 354-354v., 356$356 \mathrm{v} .$, AHNCH.
} 
su parte, Hainsworth logró resguardar el interés patrimonial de la firma apegándose a los convenios firmados en Arica, no así su prestigio. ${ }^{12}$

\section{El NACIMIENTO DE HAINSWORTH Y COMPAÑÍA Y SU IDENTIDAD COMERCIAL}

Mientras tanto, las habituales operaciones de habilitación y adelanto de mercaderías hacia Bolivia y el sur peruano fueron confiadas a John Davies Campbell, un joven inglés de 24 años contratado en mayo de 1855 y que tuvo una formación similar a la de Hainsworth. ${ }^{13}$ El término de la construcción del ferrocarril Arica-Tacna y el retiro de Hegan a Gran Bretaña, empujaron a Hainsworth a dar un salto en su carrera empresarial e iniciar un camino propio para conquistar un espacio en el comercio del Pacífico sudamericano, objetivo para el cual el apoyo de Campbell sería decisivo. La emancipación mercantil de Hainsworth comenzó en septiembre de 1856, cuando formó en Valparaíso la sociedad Farmer, Hainsworth y Compañía en conjunto con John Farmer, un antiguo colaborador en los emprendimientos mineros de Hegan y Hall. La escritura de constitución señala que Hainsworth viajará a Londres para entenderse con clientes y proveedores y que la firma tendrá una agencia en Tacna a cargo de Campbell, responsable por las operaciones en la región, en Perú y en Bolivia. ${ }^{14}$

Pero la sociedad con Farmer resultó infructuosa, pues no registra actividades luego de su fundación. A partir de julio de 1857 Hainsworth selló su alianza con Campbell, al formar juntos en Tacna Hainsworth y Compañía, con capital de 70000 pesos, de los cuales aportó 50000 pesos. $^{15}$ Además de esta cuantiosa suma (considerando que ese año las utilidades de la sucursal en Tacna de la casa Gibbs fueron de 9232 pesos), ${ }^{16}$ las operaciones de la firma partieron sobre la base de la administración de los intereses de Hegan en la región, aunque para abastecerse de importaciones abandonaron la línea seguida por este y optaron por recurrir a

\footnotetext{
${ }^{12}$ Informe del cónsul chileno en Arica a su ministro, Arica, 14 de febrero de 1856 . Fondo Perú, vol. 43, fs. 171-178, Archivo Histórico del Ministerio de Relaciones Exteriores de Chile.

${ }^{13}$ Poder de representación general, Tacna, 3 de mayo de 1855. FNA, vol. 134, fs. 338-343v., AHNCH.

${ }^{14}$ Poder de representación general, Tacna, 6 de septiembre de 1856. FNA, vol. 139, fs. 305v.310v., AHNCH.

${ }_{15}^{15}$ Constitución de sociedad anónima, Tacna, 27 de julio de 1857. FNA, vol. 141, fs. 72-76v., AHNCH.

${ }^{16}$ Balance del 1 de mayo de 1856 al 30 de abril de 1857. Balances de la Casa Gibbs, rollo 20, fs. 238-261, Colección de Microfilms de la Biblioteca de Humanidades de la Pontificia Universidad Católica de Chile.
} 
los mayoristas de Valparaíso, para lo cual designaron a James Heyword agente en ese puerto. ${ }^{17}$

No obstante nunca abandonar la distribución de manufacturas, el perfil comercial de Hainsworth y Compañía se distinguió de la mayoría de los mercaderes europeos del Pacífico sudamericano por especializarse en la compra y ejecución de deudas difíciles de cobrar. Estas operaciones, que suponían grandes riesgos así como grandes utilidades, precisaban de cualidades que pocos comerciantes de la época reunían. Primero, era necesario manejar información precisa sobre negocios en curso que atravesaban por conflictos y en cuya intervención era posible obtener dividendos; luego, era indispensable contar con capacidades de gestión judicial y administrativa para ejecutar deudas que la mayor parte del mercado consideraba incobrables y, además, era necesario tener la habilidad psicológica para persuadir a los acreedores de asumir una mala decisión, aceptar que ella supone un menoscabo patrimonial y que vender sus derechos era una buena oportunidad para disminuir las pérdidas.

Entre este tipo de operaciones sobresale la que tuvo lugar el 17 de octubre de 1862, cuando John Campbell adquirió las deudas que la sociedad boliviana Aramayo Hermanos tenía con la casa Gibbs por 56065 pesos, y con George Hellmann por 6823 pesos. La deuda con Gibbs fue contraída el 5 de septiembre de 1856 y con Hellmann el 17 de junio de 1858, en los dos casos existían cobranzas judiciales en curso y ambos acreedores cedieron sus derechos a cambio de las "cantidades convenidas", fórmula retórica empleada en las escrituras de traspaso que impide conocer la utilidad obtenida por Hainsworth. En este caso, la sociedad sabía de la gravitación de la familia Aramayo en Bolivia, su influencia en la esfera pública, su estrecha vinculación con la minería del cobre, la capacidad que tenía de saldar el pasivo con la cesión de inmuebles y derechos mineros, y la certeza de que dificultándole el acceso a las vías de exportación en Arica la obligaría a cumplir el compromiso. ${ }^{18}$

En cambio, la compra de la deuda del comerciante tacneño Marcelino Arriaga en marzo de 1864, contraída inicialmente en agosto de 1858, se ajustó a los acontecimientos cotidianos del mercado tacneño, ya que el deudor era un antiguo cliente de Hainsworth. Arriaga había sido habilitado con 1117 pesos en mercaderías por Braillard Hermanos, y con 3309 pesos por Alsop y Compañía de Valparaíso, compromisos que fueron adquiridos en una suma no indicada. ${ }^{19}$ Estos 4426 pesos se agregaban a una

${ }^{17}$ Poder de representación general, Tacna, 16 de noviembre de 1857. FNA, vol. 141, fs. 445$450, \mathrm{AHNCH}$.

${ }^{18}$ Traspaso de deuda, Tacna, 17 de octubre de 1862. FNA, vol. 174, fs. 338-344, AHNCH.

${ }^{19}$ Traspaso de deuda, Tacna, 3 de marzo de 1864. FNA, vol. 176, fs. 185-193, AHNCH. 
deuda de 13770 pesos que Arriaga tenía con Hainsworth desde agosto de 1858, garantizada con una casa de dos pisos en la calle Constitución y un sitio contiguo a ella. El 8 de marzo de 1865 Hainsworth y Arriaga acordaron eliminar todo el pasivo a cambio de los dos inmuebles, avaluados en 15 000, más el traspaso de una deuda por 6065 pesos que Exequiel Hurtado mantenía con Arriaga. ${ }^{20}$

Habitualmente los agentes de Hainsworth, John Campbell, Joseph Outram y Thomas Lansig permanecían atentos al devenir mercantil en Tacna y Arica para detectar oportunidades para transformar negocios críticos de otros en ganancias para la firma. Colaboraban a este propósito sus propias operaciones de crédito y adelanto. Un caso así lo ofreció el francés Enrique Klauer, empresario de discreta relevancia, especializado en mediar entre los grandes distribuidores y los comerciantes al menudeo, y cuya fragilidad radicaba en tener que enfrentar a poderosos acreedores y cobrar deudas a clientes muy precarios. Para aliviar las obligaciones que mantenía con la firma, en abril de 1865 Hainsworth se hizo cargo de cobrar a Daniel Bellagamba los 12000 pesos que Klauer le había prestado para surtir su tienda en Tacna. Aquí, el atractivo del negocio no radicaba en las garantías empeñadas o en los activos del deudor, sino en que el préstamo inicial estaba avalado por George H. Nugent, un próspero comerciante británico y cónsul de su país en Arica que contaba con suficientes recursos para responder por los compromisos de Bellagamba. ${ }^{21}$

La habilidad para comprar deudas complejas y ejecutarlas se extendió hasta Bolivia. Hainsworth aprovechó sus frecuentes viajes para adquirir letras de cambio suscritas por mercaderes tacneños ya vencidas, o que sus beneficiarios tenían pocas esperanzas de cobrar, ya que ejecutarlas judicialmente las hacía poco rentables. Mientras tanto, en Tacna Campbell se valía de su experiencia en tribunales para protestar estos documentos y hacer efectivas las garantías, o bien, para negociar con los deudores una salida razonable. Entre octubre de 1857 y agosto de 1862 la firma registra doce operaciones de este tipo por un valor nominal de casi 11500 pesos. $^{22}$ Como de costumbre, los documentos no indican las sumas en que estos bonos fueron comprados y luego cancelados, aunque dejan ver que su tramitación era simultánea a otros negocios de Hainsworth, que la distancia y la falta de información fresca no representaban dificultades sino factores favorables, y que la rentabilidad de estos negocios, aunque marginal, con-

${ }^{20}$ Venta de vivienda y renegociación de deuda, Tacna, 10 de marzo de 1865. FNA, vol. 178, fs. 100v.-102, AHNCH.

${ }^{21}$ Traspaso de deuda, Tacna, 24 de abril de 1865. FNA, vol. 180, fs. 231v.-232, AHNCH.

${ }^{22}$ Protesto de letras. Fondo Notarial de Tacna, vol. 14, fs. 294-294v., 297-298v., 312-312v., 318-319v., 343-343v., 352-354v., 368-368v. y 411-411v., AHNCH. 
tribuía a ampliar sus utilidades aprovechando tiempo y recursos destinados a otros proyectos.

\section{Los negocios cotidianos}

Junto a la búsqueda de brechas en los negocios ajenos, el grueso de las actividades de Hainsworth y Compañía se ajustaba al canon tradicional de adelantar manufacturas en Bolivia y el sur peruano. Una idea del volumen y características de estas operaciones la ofrece el acuerdo suscrito en septiembre de 1858 con Fermín Telles, mercader tacneño avecindado en Oruro. Según la escritura, Telles recibiría 10000 pesos en productos importados, cantidad que debía devolver en un año, a 1\% mensual, con la prenda de una casa de dos pisos en Tacna. Este contrato muestra las oportunidades de que disponía la firma por el hecho de operar en Tacna, pues además de involucrar una importante suma y una atractiva garantía, se trataba de un cliente valioso. ${ }^{23}$ En ese momento Telles era el patriarca de una antigua familia de arrieros que poseía mulas, troperos experimentados y terrenos de talaje para atender las caravanas que atravesaban la sierra. Y lo más importante, contactos en Bolivia para vender rápido los productos y quedar en condiciones de hacer nuevas compras (Rosenblitt, 2013a, p. 77).

Las características del comercio criollo de Tacna no se agotaban en las familias de grandes arrieros, pues había otras dueñas de recuas más pequeñas, que requerían de menos mercaderías, eran financieramente más frágiles y, por lo tanto, no eran clientes atractivos para Hainsworth. Estos empresarios, que combinaban el transporte con el comercio, acudían a los almacenes del pueblo para adquirir mercaderías y obtener créditos con la hipoteca de sus animales, aperos y fincas. En cambio, eran de interés para Hainsworth los propietarios de dichos establecimientos, que debían abastecerse recurriendo a créditos a $12 \%$ anual y asumir el riesgo de habilitar a clientes de escasa solvencia y poco apegados a la formalidad legal.

El 26 enero de 1860 la firma británica comenzó a conocer de cerca a estos clientes. Ese día suscribió un contrato con Pilar Pimentel para administrar los bienes comerciales de su marido, Juan Vidal, debido a una enfermedad que le impedía atender sus negocios. El acuerdo que convirtió a Hainsworth en depositario de los bienes de Vidal comenzó con un ajuste de cuentas entre las partes, que registró 28264 pesos en mercaderías adelantadas a Vidal desde julio de 1858 , de los cuales quedaba una

\footnotetext{
${ }^{23}$ Préstamo con hipoteca, Tacna, 26 de agosto de 1868. FNA, vol. 144, fs. 194v.-199, AHNCH.
} 
pequeña cantidad pendiente y que se saldaría a la brevedad. ${ }^{24}$ La gestión de Hainsworth desechó a los clientes pequeños y se concentró en aquellos capaces de asumir compromisos por un mínimo de 1000 pesos y garantizarlos con algún bien raíz. En esta categoría entraban sencillos troperos y medianos mercaderes que para ser habilitados debían reconocerse como deudores de mayor riesgo y aceptar préstamos a $2 \%$ mensual.

Pero esta pauta no podía aplicarse a todos los asuntos que los Vidal Pimentel confiaron a Hainsworth, ya que por tratarse de una familia criolla existían lazos sociales y familiares que imponían criterios subjetivos en la toma de decisiones. Una contradicción así comenzó en noviembre de 1862, cuando Juan Luis Vidal, hijo de Juan y Pilar, formó una sociedad con el francés Eduard Bernard para abrir una peluquería en Tacna. La escritura señala que la sociedad contaba con 5901 pesos, conformados por 505 en muebles aportados por Bernard y 5396 pesos prestados por Pilar Pimentel a su hijo, a devolver en cinco cuotas semestrales a $1 \%$ y garantizados con los bienes del local. ${ }^{25}$ Cuatro meses después la sociedad se disolvió y sólo tenía activos para responder por 2698 pesos. El resto debía ser devuelto por Juan Luis Vidal, aunque sin que su madre le impusiera plazos y penas por mora. ${ }^{26}$

Es imposible conocer en detalle cómo influyeron las relaciones familiares en los asuntos comerciales, pero un testamento formalizado por Pilar Pimentel en junio de 1863 ofrece algunas señales. El documento indica préstamos que hizo por 13750 pesos, de los cuales 7250 correspondían a su hijo. Luego enumera deudas que sumaban 4175 pesos e instruye a su albacea, John Campbell, de obligar a Juan Luis a cubrir los compromisos con sus acreedores a cambio de olvidar el saldo de lo adeudado a ella. ${ }^{27}$ Es probable que la generosidad empeñada por Pilar Pimentel, asumiendo la pérdida de más de 3000 para extinguir la deuda del hijo, no fuera del agrado de Hainsworth. Sin embargo, la experiencia permitió a la firma conocer de cerca la forma como operaban los pequeños mercaderes, que muchas de sus decisiones estaban guiadas por sentimientos, sensaciones y estados de ánimo y que, utilizadas con astucia y oportunamente, esas variables permitirían lograr buenos negocios.

${ }^{24}$ Poder de administración general y ajuste de cuentas. Tacna, 26 de enero de 1860 . FNA, vol. 152 , fs. $137 \mathrm{v} .-143$, AHNCH.

${ }^{25}$ Formación de sociedad comercial, Tacna, 18 de noviembre de 1862. FNA, vol. 161, fs. 418$418 \mathrm{v} .$, AHNCH.

${ }^{26}$ Disolución de sociedad comercial, Tacna, 18 de marzo de 1863. FNA, vol. 170, fs. 43-44, AHNCH.

${ }^{27}$ Testamento de Pilar Pimentel, Tacna, 19 de junio de 1863. FNA, vol. 175, fs. 197-198v., AHNCH. 


\section{Oportunidades en la minería}

La experiencia acumulada en el comercio, la ejecución de obras de infraestructura y la especulación con deudas y bonos fue puesta en práctica a inicios de la década de 1860, cuando Hainsworth y Compañía trasladó sus inversiones hacia la industria del salitre en Tarapacá. Esta decisión fue común entre los principales mercaderes tacnoariqueños, que vislumbraban que las dificultades que surgían para acceder al mercado boliviano y mantener el control sobre la exportación de materias primas, en especial el cobre de Corocoro, irían en aumento, por lo que dirigir sus intereses hacia la emergente exportación de nitratos era una conveniente alternativa, dado el incremento de la demanda mundial de fertilizantes y que allí no regían las restricciones impuestas por el Estado peruano para ingresar al negocio del guano (Miller y Greenhill, 2011b, pp. 122-125).

Pero estas mismas favorables perspectivas dificultaban el acceso de los mercaderes tacneños al negocio del salitre. La actividad estaba dominada por casas de Valparaíso que disponían de mayores capitales, controlaban los canales de distribución y se vinculaban con los productores a través del adelanto de insumos, alimentos y otros bienes, imposibilitándoles repetir el método de asentarse como comerciantes e invertir sus utilidades en la minería (Miller y Greenhill, 2011a, pp. 42-43). Por lo tanto, para ocupar un lugar en la industria los capitales tacnoariqueños financiaron trabajos en áreas aún poco explotadas, como los yacimientos del sector septentrional de la pampa, o bien buscaron grietas en los circuitos que ya funcionaban en la zona más al sur, aquella que vaciaba su producción a través de Iquique, para ocupar un espacio entre los productores criollos y los mayoristas de Valparaíso. Siguiendo esta alternativa, en mayo de 1860 Hainsworth abrió una agencia en Iquique para cuya administración recurrió a la colaboración de su conocido Guillermo Billinghurst, que después de concluir la construcción del ferrocarril Tacna-Arica había acumulado una valiosa experiencia en la actividad, siendo incorporado en calidad de socio en comandita. La agencia comenzó con un capital de 35000 pesos, 10000 de los cuales fueron aportados por Billinghurst. ${ }^{28}$

Dada su naturaleza, más especulativa que industriosa, las principales operaciones salitreras de Hainsworth se ajustaron a la regla de encontrar a algún agente ya activo y en situación crítica. La ocasión se presentó a fines de 1861, cuando John Campbell fue contactado por Adolfo Moissant, un empresario francés de Iquique que tenía un convenio con Sorucco y Compañía, de Valparaíso, para suministrarle una partida de salitre ava-

${ }^{28}$ Formación de sociedad comercial en comandita, Tacna, 23 de mayo de 1860. FNA, vol. 152, fs. 713-716, AHNCH. 
luada en 10000 pesos a más tardar el 31 de marzo entrante, y que estaba seguro no poder cumplir. Los derechos del contrato fueron traspasados a Hainsworth, que gracias a la eficacia de Billinghurst logró cumplir el acuerdo y obtener el pago de la mitad de la suma comprometida, más la cantidad (una vez más no indicada) entregada por Moissant para lograr su intervención. $^{29}$

Las utilidades de esta operación se sumaban a los contratos que Hainsworth mantenía con pequeños productores, que le permitían obtener las partidas de salitre necesarias para atender los requerimientos de clientes en Valparaíso e Iquique. ${ }^{30}$ Se trataba de mineros criollos habituados a las condiciones inhóspitas del desierto que eran habilitados con dinero e insumos para las faenas, con bajos niveles de inversión, y que durante la década de 1860 concentraron la producción de nitratos dada la alta calidad del caliche disponible en la pampa de Tarapacá. Uno de estos casos es el de Manuel Montealegre, vecino de Camiña (quebrada a 250 kilómetros al sur de Arica), que en abril de 1860 fue habilitado con 6665 pesos a 1\% mensual. Dos años más tarde la deuda había sido rebajada en 2815 pesos mediante la entrega de salitre. Al parecer, Montealegre no continuó cumpliendo, pues el 17 de mayo de 1864 Campbell inició los trámites para ejecutar la hipoteca que garantizaba el préstamo. ${ }^{31}$

La principal operación salitrera en que intervino Hainsworth fue la adquisición de parte importante del pasivo de la sociedad Naylors, Conroy y Compañía, que en mayo de 1863 se había declarado en quiebra y citado a una junta de acreedores en Tacna. ${ }^{32}$ Desde el punto de vista de las estrategias mercantiles, el desafortunado final de Naylors y Conroy representa el ocaso de los procedimientos empleados por la primera oleada de comerciantes británicos llegados a Sudamérica después de la independencia, fundamentados en el principio de ocupar un lugar en los mercados regionales distribuyendo manufacturas e invertir sus utilidades en algún circuito de exportación de materias primas, sin analizar con cuidado las singularidades de cada rubro. En cambio, Hainsworth examinaba con detención cada negocio en el que participaba, distribuía sus inversiones entre

\footnotetext{
${ }^{29}$ Venta de salitre, Tacna, 4 de abril de 1862 . FNA, vol. 168, fs. 226-232, AHNCH.

${ }^{30}$ Óscar Bermúdez (1963, p. 272) menciona a Hainsworth y Compañía como "firma inglesa, instalada en Valparaíso, atendía en ese puerto y en Santiago varios rubros comerciales, entre estos el de servir de aviadores a varios salitreros de Tarapacá, necesitados de recursos para continuar sus labores. Hainsworth les avanzaba fondos y les compraba la producción de salitre que pagaba con mercaderías y útiles de trabajo." Más adelante señala que en 1868 su agente John D. Campbell, "radicado en Tacna se interesó en el salitre. Asociado con Mr. Outram y John Syers Jones constituyeron la compañía The San Antonio Nitrate and Iodine Co."

${ }^{31}$ Poder para cobrar deuda, Tacna, 17 de mayo de 1864. FNA, vol. 176, fs. 484v.-485v., AHNCH.

${ }^{32}$ Ajuste de cuentas y traspaso de activos, Tacna, 23 de mayo de 1863. FNA, vol. 172, fs. 455465 , AHNCH.
} 
varias actividades y aprovechaba sus fortalezas operativas, con lo que evitaba riesgos significativos.

Formada en Lima a comienzos de 1850, la sociedad entre George Naylors y Peter Conroy encarnaba el accionar de las primeras firmas británicas asentadas en la costa del Pacífico, dada la experiencia previa de Naylors, que llegó a Tacna en septiembre de 1837 en una comitiva enviada desde Río de Janeiro por Naylors, Kendall y Compañía, firma de la que su padre era socio mayoritario. ${ }^{33}$ Aunque se radicó en Lima, el joven Naylors mantuvo sus intereses en el mercado tacneño a través de ventas de manufacturas y sociedades con otros británicos para exportar materias primas bolivianas. Ya en compañía de Conroy decidió incursionar en la colocación de cobre, pues creía disponer de bajos costos de transporte que le permitirían llegar al mercado británico con precios convenientes (Rosenblitt, 2013a, pp. 258-259; Witt, vol. II, 1992, pp. 145-146). Para obtener el mineral la compañía adquirió algunas estacas en Corocoro, que intentó explotar asociándose con empresarios locales. Los indicios disponibles sugieren que la experiencia fue negativa, pues en junio de 1853 abrió una sucursal en La Paz y asignó su dirección a George Buchannan, con el encargo especial de "cobrar las cantidades de cobre que adeudan Manuel María Vila y la testamentaria de Tejada". ${ }^{34}$

La misión fracasó porque diez meses después Naylors y Conroy entró en proceso de quiebra, encomendándose a George Hellman ajustar sus cuentas en Tacna. La gestión de Hellman revela el heterogéneo conjunto de inversiones hechas por la sociedad y sus erradas decisiones. Entre estas destaca la compra al general Otto Braun, en mayo de 1851, de las minas Santa Felicidad y San Juan Bautista en Corocoro por 75000 pesos, pagados con letras giradas por comerciantes de Liverpool. Además, la firma suscribió contratos con Narciso Aranda, Juan Mas y José Prohias para recibir remesas de cobre por más de 3000 pesos mensuales, todos fracasados y con juicios para ejecutar las prendas sobre pertenencias mineras e inmuebles que garantizaban los adelantos hechos por 6 726, 7397 y 3864 pesos respectivamente. ${ }^{35}$

La información reunida no ofrece certeza si acaso Naylors y Conroy planificaron mantener separadas sus inversiones en el cobre boliviano de

${ }^{33}$ Poder de representación en la reorganización de Naylors Hermanos y Compañía, de Río de Janeiro, Tacna, 10 de diciembre de 1846. FNA, vol. 107, fs. 518-519v., AHNCH.

${ }_{35}$ Contratos de habilitación minera, Tacna, 3 de octubre de 1862 y 5 de junio de 1855 . FNA,

${ }^{34}$ Poder de representación general, Tacna, 3 de junio de 1853. FNA, vol. 130, fs. 574v.-577v., vol. 174, fs. 293 v.-303 y vol. 134, fs. 447-449; Demanda por incumplimiento de contrato de habilitación minera, Tacna, 9 de julio de 1858. Fondo Judicial de Arica, leg. 123, pieza 6, ambos fondos en AHNCH. 
las hechas en el nitrato de Tarapacá como una forma de moderar los riesgos sobre todo su capital; si su entrada al negocio del salitre tuvo por propósito obtener rentas para paliar las pérdidas en las inversiones cupríferas, o si la compañía estaba previamente comprometida a colocar salitre en el mercado británico. El hecho es que en febrero de 1856, cuando ya se había iniciado el proceso de quiebra, la firma se asoció con Guillermo Billinghurst en la Sociedad Explotadora de Salitres, de la que se desconoce el capital inicial. Naylors aportaba depósitos de caliche cerca de Iquique y capital fresco, mientras que el ingeniero sumaba sus conocimientos técnicos y experiencia, pues quedó a cargo de la dirección de los trabajos. ${ }^{36}$

La decisión de extraer y procesar directamente salitre tampoco fue correcta, pues en octubre de 1862 la empresa arrojaba serias pérdidas y los socios designaron abogados para deslindar responsabilidades y establecer los montos involucrados..$^{37}$ Las inversiones salitreras de Naylors y Conroy incluían también adelantos a productores independientes, como Agustín Loayza, habilitado con 20 764; Eugenio Castilla, con 5 265, y Diego Castro, con 3735 pesos. Todos ellos bajo la modalidad de créditos a $1 \%$ mensual, a pagar en nitrato refinado y garantizados con la hipoteca de sus instalaciones. ${ }^{38}$

En mayo de 1863, cuando la continuidad de Naylors y Conroy era ya insostenible, Hainsworth apareció en escena para hacerse con sus activos más valiosos. El día 23 George Hellman y John Campbell terminaron esta agonía, acordando el traspaso de todos los inmuebles y deudas por cobrar en Tacna e Iquique a cuenta de los compromisos pendientes de Naylors con Hainsworth, entre los que había préstamos asignados directamente y deudas compradas a terceros. Se reconocía que se mantenía un saldo del pasivo y que, para cubrirlo, Hainsworth tendría preeminencia cuando se efectuara el concurso de acreedores. En otra escritura Campbell le traspasó a Guillermo Billinghurst todos los bienes y obligaciones a favor de Naylors y Conroy en Tarapacá a cambio del saldo a su favor derivado del juicio de la Sociedad Explotadora de Salitres y "una cantidad de dinero fijada de común acuerdo". ${ }^{39}$

${ }^{36}$ Formación de Sociedad Explotadora de Salitres, Tacna, 11 de febrero de 1856. FNA, vol. 138, fs. 114.119v., AHNCH.

${ }^{37}$ Arbitraje para disolución de Sociedad Explotadora de Salitres, Tacna, 31 de octubre de 1862. FNA, vol. 174, fs. 429v.-439v., AHNCH.

${ }^{38}$ Contratos de habilitación salitrera, Tacna, 25 de noviembre de 1859, 2 de febrero y 8 de mayo de 1860 . FNA, vol. 147, fs. 28v.-29, 38v.-39 y 51-51v., AHNCH.

${ }^{39}$ Traspaso de activos y deudas, Tacna, 23 de mayo de 1863 . FNA, vol. 172, fs. 455-465 y 465$467 \mathrm{v}$. , AHNCH. 


\section{Otros proyectos}

La capacidad de Hainsworth y Compañía de transformar proyectos críticos en utilidades se extendía también a inversiones de menor cuantía que las mineras, que en teoría disponían de condiciones para ser rentables, aunque los cálculos erróneos de sus promotores impidieron su éxito. Una oportunidad así se presentó en agosto de 1862, cuando la sociedad entre los franceses Fernando Hugues y Carlos Fréraut entregó a Hainsworth la administración provisional para pedir su quiebra. ${ }^{40}$ Formada en diciembre de 1860 bajo la denominación Hugues y Compañía, la firma instaló una planta industrial para destilar aguardiente en el extremo norte de Arica, gracias a créditos recibidos del propio Hainsworth y de Naylors y Conroy. El proyecto debía ser la culminación de la trayectoria de Fernando Hugues iniciada en 1846, cuando comenzó a colaborar en la pulpería de su hermano Aimé atendiendo a arrieros y mercaderes que viajaban hacia Bolivia. Después de reunir un pequeño capital y asociarse con su compatriota Juan Millet, en abril de 1853 abrió bodegas en La Paz y Oruro dedicadas a la distribución de aguardiente, alimentos, manufacturas y con la intención de "llevar a cabo cualquier negocio mercantil o mineralógico que se presentase". Pero la falta de oportunidades efectivas para integrarse al sector minero y la presencia de numerosos y mejor dotados comerciantes de importaciones, obligó a los socios a concentrarse en la venta de licor. Para ello contaban con la ventaja de que Hugues podía obtener aguardiente en Tacna y sus valles vecinos, aunque los procesos de producción artesanal imperantes no garantizaban la calidad del destilado ni los volúmenes necesarios para abastecer la demanda en Bolivia. Por ello, Hugues decidió innovar y emprender la destilación industrial (Rosenblitt, 2017b, pp. 15-17).

Pero el negocio no arrojó frutos, ya que la modernización productiva continuó dependiendo de las formas tradicionales de comercialización. Es decir, el licor producido era entregado a pequeños distribuidores y arrieros que trajinaban hacia Bolivia mediante acuerdos de habilitación suscritos a través de tratos de palabra que, en el mejor de los casos, eran respaldados por letras de cambio, lo que hacía muy difícil demandar incumplimientos de los compromisos. Al mismo tiempo, los créditos recibidos por Hugues y Fréraut fueron suscritos en contratos que establecían penas por mora y garantías hipotecarias. Como el consumo del aguardiente regional descansaba en la demanda de los enclaves mineros bolivianos y este sector experimentó una contracción entre 1856 y 1863 (Castro, 1995, p. 78; Seminario, 2016, p. 784), la consiguiente caída en la demanda altiplánica AHNCH.

${ }^{40}$ Liquidación de sociedad comercial, Tacna, 26 de agosto de 1862. FNA, vol. 174, fs. 117-119, 
dejó a la empresa en la situación de desgastarse tratando de cobrar compromisos vencidos a deudores escurridizos mientras negociaba nuevos plazos con acreedores muy rigurosos. En julio de 1862 la situación se hizo insostenible y el juez de Tacna dictaminó la quiebra. Afortunadamente para Hugues y Fréraut, en junio de 1863 Campbell aceptó recibir la planta destiladora, 2000 pesos en efectivo y el traspaso de las deudas vencidas y letras por cobrar a cambio de 20063 pesos más intereses que reclamaba Hainsworth y Compañía, quedando pendientes 4087 pesos adeudados originalmente a Naylors y Conroy, que debían ser restituidos en cuotas semestrales de 500 durante cinco años. ${ }^{41}$

Otro rubro novedoso explorado por Hainsworth fue la captación de ahorrantes interesados en invertir en depósitos a plazo, motivados por rentabilizar capitales inmóviles o para asegurar un ingreso futuro a familiares. Para eso obtuvo la representación en Perú de la compañía El Porvenir de las Familias, creada en Santiago de Chile en enero de 1856 con un capital de 100000 pesos. Como principal objetivo, la firma se proponía emitir suscripciones para captar fondos que invertir en diversas empresas, de modo que las utilidades de estas colocaciones incrementaran el valor de sus bonos (El Porvenir de las Familias, 1857).

La documentación reunida no ofrece antecedentes precisos sobre cuándo Hainsworth comenzó a ofertar las suscripciones, exactamente quiénes participaron ni qué suma logró reunir. Se sabe que entre los inversionistas locales había criollos y extranjeros ligados al comercio y la agricultura, y que a partir de febrero de 1862 muchos comenzaron a gestionar la devolución de sus inversiones, la mayor parte a través de abogados contratados en Chile, ya que Hainsworth no había garantizado los depósitos ni los dividendos. Uno de estos casos es el del coronel Celestino Vargas, hacendado del valle de Locumba con activa participación en la política local, que solicitó el reembolso de las tres suscripciones hechas a nombre de sus hijos por 1500 pesos, que después de cinco años y agregados los intereses sumaban 2 134. Vargas se resignaba a recuperar sólo el dinero confiado al comienzo de la operación, dejando a Hainsworth las eventuales utilidades que pudieran existir. El intento no tuvo resultados favorables ya que a partir de mayo de 1862 numerosos inversionistas -incluyendo a Hainsworth- designaron apoderados para ser representados en la liquidación de la compañía chilena. ${ }^{42}$

Más allá de los vacíos en las legislaciones peruana y chilena sobre el mercado de capitales, que evitaron que esta fallida operación le reportara

\footnotetext{
${ }^{41}$ Acuerdo pago de deuda, Tacna, 16 de junio de 1863. FNA, vol. 160, fs. 53v.-56, AHNCH.

${ }^{42}$ Solicitud de reembolso, Tacna, 7 de febrero de 1863. Fondo Notarial de Tacna, vol. 13, fs. 263-265.
} 
serias pérdidas, la participación de Hainsworth en el episodio El Porvenir de las Familias, sumada a sus negocios de compra de deudas, deja la impresión de una firma que busca alejarse de la lógica del intercambio de manufacturas por materias primas para dar un salto cualitativo a las finanzas, donde las fortalezas que se imponían eran el manejo de información fresca, una conducta audaz y confianza en el futuro.

\section{ConClusiones}

El 20 de octubre de 1865 John Davies Campbell y Joseph Outram se reunieron en la escribanía de Tacna para renovar la vigencia de la sociedad Hainsworth y Compañía por cinco años más. Campbell se representaba a sí mismo y a James Hainsworth, radicado en Liverpool, ${ }^{43}$ y Outram asumía la condición de socio minoritario de la firma en que se desempeñaba hacía tres años. La sociedad declaró un capital de 600000 pesos, de los cuales la mitad pertenecía a Haisnworth, $30 \%$ a Campbell y $20 \%$ a Outram. ${ }^{44} \mathrm{Al}$ comparar este patrimonio con los 70000 pesos con que se formó en julio de 1857 , resulta evidente el éxito de sus operaciones y que la visión sobre la evolución que tendría el comercio en la región Tacna-Arica y el Pacífico durante las décadas de 1840 a 1860 era correcta. El bosquejo presentado sobre las actividades de la firma permite derivar dos tipos de conclusiones. Primero, sobre las características del comercio y el funcionamiento de los circuitos de intercambio en la región, y luego, sobre las singularidades de la estrategia comercial desplegada por Hainsworth que explican sus aciertos.

Por el hecho de haberse vinculado con diferentes actores de la economía regional, de diversas dimensiones, características y especialidades, de los negocios de Hainsworth reseñados se desprende que el sector comercial asentado en el eje Tacna-Arica entre 1840 y 1865 estaba integrado a un circuito de intercambio que recorría el Pacífico sudamericano y cuya principal fortaleza radicaba en articular la importación de manufacturas y la exportación de materias primas a gran escala. Estaba encabezado por un grupo de comerciantes europeos, principalmente británicos, que formaba una comunidad mercantil asentada en las principales plazas de esa región, como Valparaíso, Lima, Arequipa y La Paz, que representaba o

${ }^{43}$ El establecimiento de Hainsworth en Liverpool es señalado en la escritura de renovación de su sociedad con Campbell y Outram. Desconocemos las actividades que allí desempeñó y la composición del patrimonio acumulado en Perú, pues en los registros notariales de Tacna no existe una copia de su testamento.

${ }^{44}$ Renovación vigencia sociedad comercial, Tacna, 20 de octubre de 1865. FNA, vol. 178, fs. 531-533v., AHNCH. 
se entendía directamente con firmas europeas encargadas de obtener las manufacturas demandadas localmente y colocar las materias primas en sus mercados de consumo. El eje de esta circulación era el puerto chileno de Valparaíso, desde donde se despachaban las manufacturas noratlánticas hasta los distintos mercados regionales y proporcionaba parte importante del capital y los recursos logísticos necesarios para el funcionamiento de los flujos de exportación de materias primas. ${ }^{45}$

Los mercaderes extranjeros de Tacna y Arica, ya sea como representantes o asociados de firmas extranjeras, se especializaron en atender el circuito desde y hacia Bolivia, favorecido por los acuerdos comerciales y aduaneros entre los gobiernos de Perú y Bolivia y, a partir de 1857, por la entrada en servicio del ferrocarril entre Tacna y Arica. Además, estos empresarios permanecían atentos al surgimiento de oportunidades de negocios en lugares cercanos, como la industria del salitre de Tarapacá, la minería del cobre en Bolivia, la exportación de lana y corteza de cascarilla $\mathrm{y}$ en operaciones de descuento con bonos fiscales.

Más abajo, numerosos pequeños y medianos comerciantes provinciales se ocupaban de la distribución de mercaderías y alimentos a escala local y regional. Algunos tenían almacenes en Tacna y Arica en los que atendían personalmente a sus clientes; otros llegaban desde Moquegua e Ilabaya a surtirse de manufacturas en las bodegas de los mercaderes más importantes, y otros formaban pequeñas caravanas con las que llegaban hasta lugares más alejados para vender sus productos a campesinos y comunidades indígenas. En este nivel, compartido por criollos y extranjeros, también se encuentra el comercio de alimentos, forraje, vinos y licores que, si bien no producía grandes utilidades, permitía la continuidad en el giro mercantil. Además, hubo algunas actividades inmobiliarias, como la adquisición de viviendas que luego eran subdivididas para vender o arrendar como locales comerciales.

Sobre las causas que explican el éxito de los negocios de Hainsworth y Compañía y que la mayor parte de sus decisiones fueran acertadas, se observa que, más allá de afortunadas determinaciones derivadas de correctas lecturas del mercado, manejo de información fresca o sencillamente el instinto y el azar, subyace una estrategia de negocios que entregó criterios para orientar sus inversiones. Primero, sobresale la elección de localizarse en el eje Tacna-Arica para ocupar un lugar en la distribución de manufacturas en Bolivia y las provincias meridionales de Perú y, al mismo tiempo, tomar parte en los flujos de exportación de materias primas que aquellas

\footnotetext{
${ }^{45}$ Hasta ahora Desmond C. Platt (1973) proporciona la mejor descripción sobre la estrategia de penetración del comercio británico en América Latina y las políticas de las nuevas repúblicas que favorecieron su influencia sobre las distintas economías nacionales.
} 
regiones producían, aprovechando las cualidades geográficas del eje Tacna-Arica y las ventajas administrativas que prodigó el Estado peruano a los mercaderes allí asentados.

Pero Hainsworth no fue el único actor comercial que valoró estas condiciones y siguió la regla de distribuir importaciones y exportar materias primas. La diferencia a su favor radica en que mantuvo la atención en las actividades de otros comerciantes en busca de situaciones críticas y emprendimientos fracasados donde intervenir para enmendar errores, aprovechar liquidaciones de activos, renegociar deudas y apropiarse de inmuebles y bienes de capital por la vía judicial o de la negociación. Para ello resultó fundamental la formación que tuvieron los socios fundadores al servicio de Joseph Hegan, de quien aprendieron a cobrar deudas, tramitar la ejecución de garantías y manejar situaciones de angustia de otros mercaderes, sea como deudores o como acreedores, para llegar a acuerdos favorables. Por lo tanto, la estrategia empresarial practicada por Hainsworth no suponía intenciones de innovación productiva, ampliación y búsqueda de mercados, promover emprendimientos que comportaran algún riesgo o aventurarse en las finanzas a través de la participación en la propiedad de un banco, sino que privilegiaba intervenir en negocios en los que la incertidumbre fuese mínima y obtener utilidades allí donde otros sólo veían conflictos. Para ello Hainsworth precisaba de información actualizada, la que obtenía de sus agentes en Lima, Valparaíso, Iquique y Bolivia, que les proporcionaba el propio Hegan desde Londres, e incluso sus clientes y asociados, que en el transcurso de negociaciones o simples pláticas revelaban antecedentes propios o de otros empresarios que en algún momento podían ser útiles.

No obstante que la especulación con deudas distinguió el perfil empresarial de Hainsworth en el mercado regional, las inversiones mineras determinaron su destino. La información fidedigna y oportuna fue un factor clave en sus decisiones mineras, predominando el criterio de alejarse del cobre boliviano para integrarse a la industria del salitre en Tarapacá. La documentación examinada no ofrece certeza sobre la evaluación que tenían, a comienzos de la década de 1860, tanto los socios como otros empresarios sobre el futuro de ambos sectores, la percepción sobre cuál sería la decisión del gobierno peruano en cuanto a mantener las ventajas administrativas que favorecían las exportaciones bolivianas por Arica y las posibilidades de éxito que tendría trasladar parte importante de sus intereses hacia el salitre que, no obstante sus auspiciosas perspectivas, estaba controlado por agentes de mayor peso que dificultarían el ingreso de nuevos actores al negocio.

Los antecedentes reunidos muestran que, más allá de aprovechar circunstancias puntuales para adquirir activos, el abordaje de Hainsworth 
en el negocio salitrero fue posible gracias a la alianza con Guillermo Billinghurst, un profesional que aportó los indispensables conocimientos técnicos para insertarse en el rubro y que además ofrecía garantías de confiabilidad por el hecho de conocer a James Hainsworth desde la construcción del ferrocarril de Tacna a Arica y por tener una deuda de gratitud con John D. Campbell, que lo ayudó a resolver la situación judicial derivada de la crisis de la Sociedad Explotadora de Salitres en 1856.

Luego del terremoto y tsunami de agosto de 1868, que devastó la región y terminó casi paralizando el comercio a través del eje Tacna-Arica, la industria salitrera dejó de ser una alternativa y se convirtió en la mejor opción que los socios podían seguir. Con Hainsworth retornado a Inglaterra, Campbell y Outram iniciaron la explotación de la oficina San Antonio, en el sector norte de la región salitrera, obtenida de antiguos deudores (Bermúdez, 1963, p. 276). Para ello siguieron el camino de mantenerse en la vanguardia tecnológica logrando la colaboración del ingeniero James Humbestone, cuya fórmula de obtener nitrato procesándolo mediante la inyección de vapor a través de tubos circulares en las cubas metálicas donde se depositaba el caliche antes triturado en molinos, también impulsados por vapor, permitía rebajar los costos y obtener un salitre de mayor calidad (González, 2011, p. 171). Una década más tarde, en la víspera de la guerra del Pacífico, Campbell y Outram habían incrementado sus intereses con la adquisición de la oficina Agua Santa, mucho más cerca de Iquique que sus otros planteles, y figuraban en el elenco de los principales inversionistas extranjeros de la industria (Bermúdez, 1984, pp. 117-118), demostrando una vez más que el buen criterio estaba de su lado.

\section{LISTA DE REFERENCIAS}

Aujovín, C. (2000). Caudillos y constituciones. Perú: 1821-1845. Lima: Pontificia Universidad Católica del Perú/Instituto Riva Agüero/Fondo de Cultura Económica.

Assadourian, C. S. (1982). El sistema de la economía colonial. Mercado interno, regiones y espacio económico. Lima: Instituto de Estudios Peruanos.

Bermúdez, O. (1963). Historia del salitre. Desde sus orígenes hasta la guerra del Pacífico. Santiago: Ediciones de la Universidad de Chile.

Bermúdez, O. (1984). Historia del salitre. Desde la guerra del Pacífico hasta la revolución de 1891. Santiago: Ediciones Pampa Desnuda.

Bonilla, H. (1977). Los mecanismos de un control económico. En H. Bonilla (comp.), Informes de los cónsules británicos (vol. 5). Lima: Instituto de Estudios Peruanos/Fondo del Libro del Banco Industrial del Perú. 
Bonilla, H. (1994). Guano y burguesía. El contraste de la experiencia peruana con las economías de exportación de Perú y Bolivia (3a. ed.). Quito: Facultad Latinoamericana de Ciencias Sociales.

Castro, J. (1995). Puerto y región: Arica en el siglo XIX (1857-1877) (Tesis de maestría). Pontificia Universidad Católica del Perú, Perú.

Cavieres, E. (1988). Comercio chileno y comerciantes ingleses, 1820-1880: un ciclo de historia económica. Valparaíso: Ediciones Universitarias de Valparaíso.

Condori, V. (2014). Economía y empresa en Arequipa a inicios de la república, 18251850. Economía, 37(74), 163-212. Recuperado de http://revistas.pucp.edu.pe/index.php/economia/article/view/11416

Contreras, C. (2012). La economía pública en el Perú después del guano y del salitre, Crisis fiscal y élites económicas durante su primer siglo independiente. Lima: Banco Central de Reserva del Perú/Instituto de Estudios Peruanos.

Contreras, C. (2015). El aprendizaje de la libertad. Historia del Perú en el siglo de su Independencia. Lima: Fondo Editorial Pontificia Universidad Católica del Perú.

Díaz, A., Ruz, R., Galdames, L. y Tapia, A. (2012). El Arica peruano de ayer. Siglo XIX. Atenea, 505, 159-184. DOI: 10.4067/S0718-04622012000100008

El porvenir de las familias (1857). El porvenir de las familias. Compañia Jeneral Chilena de Seguros Mutuos sobre la vida. Reglamento Administrativo. Santiago: Imprenta del Ferrocarril.

Fernández, M. (2017). Arica de antaño en la pluma de viajeros notables. Siglos XVI-XIX. Santiago: Centro de Investigaciones Diego Barros Arana.

GonZÁlez, S. (2011). Auge y crisis del nitrato chileno. La importancia de los viajeros, empresarios y científicos, 1830-1890. Tiempo Histórico, 2, 159-178. Recuperado de http://bibliotecadigital.academia.cl/handle/123456789/1586

Gootenberg, P. (1997). Caudillos y comerciantes. La formación económica del Estado peruano, 1820-1860. Cuzco: Centro de Estudios Regionales Bartolomé de Las Casas.

McEvoy, C. (2015). La guerra maldita. Domingo Nieto y su correspondencia, 1843-1844 (t. I). Lima: Ministerio de Cultura.

Miller, R. y Greenhill, R. (2011a). El gobierno peruano y el comercio del salitre, 1873-1879. En R. Miller, Empresas británicas, economía y política en el Perú, 18501934 (pp. 11-30). Lima: Banco Central de Reserva del Perú/Instituto de Estudios Peruanos.

Miller, R. y Greenhill, R. (2011b). Las cadenas de mercancías en los fertilizantes: el guano y el salitre, 1840-1930. En R. Miller, Empresas británicas, economía y política en el Perú, 1850-1934 (pp. 116-162). Lima: Banco Central de Reserva del Perú, Instituto de Estudios Peruanos.

Moreno, A. (1977). El Corregidor de indios y la economía peruana del siglo XVIII (los repartos forzosos de mercaderías). Madrid: Consejo Superior de Investigaciones Científicas/ Instituto Gonzalo Fernández de Oviedo.

Nugent, G. H. (1976) [1866]. Puerto de Arica. Informe del Vice-Cónsul, Sr. G. H. Nugent, sobre el intercambio comercial de Arica, correspondiente a 1866. En H. 
Bonilla (comp.), Gran Bretaña y Perú, 1826-1919. Informes de los cónsules británicos (vol. IV). Lima: Instituto de Estudios Peruanos/Fondo del Libro del Banco Industrial del Perú.

Platt, D. C. (1973). Latin America and British trade, 1806-1914. Nueva York: Barnes \& Noble.

Quiroz, A. W. (2013). Historia de la corrupción en el Perú. Lima: Instituto de Estudios Peruanos.

Rosenblitt, J. (2010). El comercio tacnoariqueño durante la primera década de vida republicana en Perú, 1824-1836. Historia, 43(1), 79-112. Recuperado de http:// revistahistoria.uc.cl/wp-content/uploads/2010/11/art03.pdf

Rosenblitt, J. (2012). Tacna, su comercio y la Confederación Perú-Boliviana. Revista Histórica, 45, 189-229.

Rosenblitt, J. (2013a). Centralidad geográfica, marginalidad política: La región Tacna-Arica y su comercio, 1778-1841. Santiago: Centro de Investigaciones Diego Barros Arana.

Rosenblitt, J. (2013b). Proteccionismo, librecambismo y regionalismos en la génesis de la república peruana. En J. RosenblitT (ed.), Las revoluciones americanas y la formación de los Estados nacionales (pp. 227-247). Santiago: Centro de Investigaciones Diego Barros Arana.

Rosenblitt, J. (2014). De arrieros a mercaderes. Orígenes de los comerciantes de la región Tacna-Arica, 1776-1794. Revista de Indias, 74(260), 35-66. DOI: 10.3989/ revindias.2014.002

Rosenblitt, J. (2017a). Cuatro monopolistas extranjeros establecidos en Tacna. Prospección a los mercaderes británicos establecidos en la región Tacna-Arica, 18301861. En C. Mazzeo (ed.), Comercio, comerciantes y circuitos mercantiles en el Perú, siglos XVII a XIX. Lima: Instituto Riva-Agüero.

Rosenblitt, J. (2017b). Los circuitos comerciales en el eje Tacna-Arica durante la temprana república peruana, 1840-1863. Una aproximación a los comerciantes intermedios. Revista del Instituto Riva-Agüero, 2(2), Lima.

Seminario, B. (2016). El desarrollo de la economía peruana en la era moderna. Precios, población, demanda y producción desde 1700. Lima: Fondo Editorial Universidad del Pacífico.

Sobrevilla, N. (2015). Andrés de Santa Cruz, caudillo de Los Andes. Lima: Instituto de Estudios Peruanos/Fondo Editorial Pontificia Universidad Católica del Perú.

TantaleÁn, J. (2011). La gobernabilidad y el Leviatán guanero. Desarrollo, crisis y guerra con Chile. Lima: Banco Central de Reserva del Perú/Instituto de Estudios Peruanos.

Valdivia, J. G. (1874). Memorias sobre las revoluciones de Arequipa: desde 1834 hasta 1866. Lima: Imprenta de la Opinión Nacional.

VArgas, R. (1956). Historia del Perú. Vol. 3: El virreinato (siglo XVIII), 1700-1790. Lima: Librería e Imprenta Gil.

Wiener, Ch. (1993). Perú y Bolivia. Lima: Instituto Francés de Estudios Andinos/Universidad Nacional Mayor de San Marcos [1880, París: Hachette]. 
$70 \quad$ Jaime Rosenblitt B.

WITT, H. (1992). Diario 1824-1890. Un testimonio personal sobre el Perú en el siglo XIX (2 vols.). Lima: Banco Mercantil.

\section{Hemerografía}

El Moqueguano, Tacna, Perú.

El Pabellón Nacional, Arequipa, Perú.

El Peruano, Lima, Perú.

Archivos

AHNCH Archivo Histórico Nacional, Santiago, Chile. 